bronchoalveolar lavage fluid, Lung India. 35(4): 295-300.

4. Yanjun Lu, et al, (2018) Evaluating the diagnostic accuracy of the Xpert MTB/RIF assay on bronchoalveolar lavage fluid: A retrospective study, International Journal of Infectious Diseases 71, pp 14-19.

5. World Health Organization, (2019), Global tuberculosis report 2019,ISBN 978-92-4-156571-4, pp 1-7, $27-68$.

\title{
YẾU TỐ ẢNH HƯỞNG ĐẾN KHẢ NĂNG CHI TRẢ CHO GÓI KHÁM TƯ VẤN VÀ PHÁT HIẾN SỚM UNG THƯ VÚ TẠI KHOA TẦM SOÁT UNG THƯ, BÊ̂NH VIỆN UNG BƯỚU THÀNH PHỐ HỒ CHÍ MINH NĂM 2019
}

Nguyễn Quỳnh Anh*

\section{TÓM TẮT}

Mục tiêu: Nghiên cứu được thực hiện nhằm tìm hiểu một số yếu tố ảnh hưởng đến khả năng chi trả cho gói khám tư vấn và phát hiện sớm ung thư vú tại Khoa Tầm soát Ung thư, Bệnh viện Ung bướu Thành phố Hồ Chí Minh năm 2019. Phương pháp nghiên cứu: Nghiên cứu cắt ngang sử dụng số liệu định lượng (thu thập từ phát vấn với 240 phụ nữ) và số liệu định tính (tổ chức 2 cuộc thảo luận nhóm với 14 phụ nữ đến đăng ký khám tại Khoa Tâm soát ung thư') trong thời gian từ tháng $04 / 2019$ đến tháng 9/2019. Kết quả và kết luận: Mỗt số yếu tố ảnh hưởng đến việc lựa chọn cũng như sẵn sàng chi trả để sử dụng gói khám TSUT bao gồm bị tác động từ gia đình, người than, thu nhập của bản thân/gia đình; giá của gói dịch vụ được niêm yết; uy tín của cơ sở y tế và tính chất bệnh. Bên cạnh đó, có sự khác biệt giữa khả năng chi trả của phụ nữ với các nhóm nghề nghiệp, trong đó nhóm nhân viên văn phòng có khả năng chi trả cao hơn các nhóm nghề nghiệp còn lai; có sư khác biệt giữa khả năng chi trả của phụ nữ với thu nhập trung bình của toàn bô gia đình, trong đó thu nhập trung bình từ 30 triệu trở lên có khả nẳng chi trả cao hơn các mức thu nhập còn lại.

Từ khoá: khả năng chi trả, yếu tố ảnh hưởng, khám tầm soát ung thư, ung thư vú, bệnh viện Ung bướu

\section{SUMMARY}

SEVERAL INFLUENCING FACTORS ON ABILITY TO PAY OF AN ON-SERVICE BREAST CANCER COUNSELING AND EARLY

DETECTION PACKAGE AT HO CHI MINH CITY ONCOLOGY HOSPITAL, 2019

Objective: The study was conducted to understand some influencing factors on the ability to pay of an on-service breast cancer counseling and early detection packages at the Department of Cancer Screening, Ho Chi Minh City Oncology Hospital in 2019. Methods: Cross-sectional study using

*Trường Đại học Y tế Công Cộng

Chịu trách nhiệm chính: Nguyễn Quỳnh Anh

Email: nqa@huph.edu.vn

Ngày nhận bài: 22.2.2021

Ngày phản biên khoa học: 29.3.2021

Ngày duyệt bài: 5.4.2021 quantitative data collected from interviewing with 240 women and group discussion with 14 women registered at the Department of Cancer Screening between April 2019 and September 2019. Results and conclusions: A number of factors influencing the choice of as well as the willingness to pay to use the early detection package include family impacts, coalitioners, self/family income; the listedprice of the service package; reputation of hospital and the nature of the disease. In addition, there is a difference between women's affordability and occupational groups, in which office workers are more likely to pay than the rest of the occupation groups. There is also a difference between women's ability to pay and the average income of the whole family, with an average income of 30 million or more being more affordable than the rest of the income groups.

Keywords: ability to pay, counseling and early detection packages, breast cancer, Ho Chi Minh City Oncology Hospital

\section{I. ĐĂT VẤN ĐỀ}

Năm 2018, theo thống kê của Cơ quan quốc tế nghiên cứu về ung thư GLOBOCAN tại Việt Nam, tổng số ca măc mới ung thư nhiêu nhất thuộc về ung thư gan (23.335 trường hợp), tiếp đến là ung thư phổi (23.667 trường hợp), ung thư dạ dày (17.527 trường hợp) tiếp theo là ung thư đại trực tràng (14.272 trường hợp) và ung thư vú (15.229 trường hợp)(1). Ung thư vú (UTV) là bệnh ung thư hay gặp nhất ở phụ nữ và là nguyên nhân gây tử vong cao tại các nước trên thế giới. Tại Việt Nam, theo nghiên cứu gánh nặng bệnh ung thư và chiến lược phòng chống ung thư quốc gia đến năm 2020 cho thấy UTV là bệnh có tỷ lệ mới mắc cao nhất trong các ung thư ở nữ giới (2). Mặc dù tỷ lệ mắc UTV có xu hướng tăng trong những năm gần đây nhưng tỷ lệ tử vong do bệnh vẫn từng bước được cải thiện nhờ các thành tựu đạt được trong phòng bệnh, phát hiện bệnh sớm, chẩn đoán và điêu trị. Việc tâm soát ung thư sẽ giúp người dân phát hiện bệnh sớm, tăng khả năng điêu trị thành cồng, giảm quá tải cho hệ thống y tế khi phải điều trị cho bệnh nhân ở giai đoạn bệnh 
năng. Bên canh đó, mức chi phí bình quân cho việc điều trị nội trú và khám chữa bệnh ngoại trú ở nước ta đang trong xu hướng tắng dân thời gian qua, vì vậy khả năng chi trả của người dân khi sử dụng/thụ hưởng một loại dịch vụ y tế luôn chịu tác động bởi nhiều yễu tố chủ quan và khách quan, đặc biệt là mối liên quan giữa đặc điểm cá nhân, loại bệnh với khả năng chi trả(3).

BV Ung bướu TP. HCM đã cung cấp gói tầm soát phát hiện sớm ung thư tuyễn vú. Sau một thời gian triển khai, Ban giám đốc bệnh viện cần có những bằng chứng khoa học và chính xác về việc triển khai gói dịch vụ tầm soát ung thư, cự thể là trả lời các câu hỏi liên quan đến thực tể khả năng chi trả và một số yếu tố ảnh hưởng khi người bệnh sử dụng gói dịch vụ theo yêu cầu như thế nào? Vì vậy, nghiên cứu "Yếu tố liên quan đến khả năng chi trả cho gói khám tư vấn và phát hiện sớm ung thư vú tại Khoa Tầm soát Ung thư, Bệnh viện Ung bướu Thành phố Hồ Chí Minh năm 2019" được thực hiện nhằm cung cấp thông tin để Ban giám đốc có chính sách phù hợp về giá gói dịch vụ để tăng tính tiếp cận cho người dân có nhu câu sử dụng dịch vụ tầm soát ung thư vú.

\section{II. ĐỐI TƯỢNG VÀ PHƯƠNG PHÁP NGHIÊN CỨU}

Thiết kế nghiêncứu: nghiên cứu cắt ngang sử dụng số liệu định lượng kết hợp định tính

Đối tượng nghiêncứu: Phụ nữ có nhu cầu sử dụng (bao gồm đã từng khám và chưa từng khám) gói dịch vụ khám tư vấn và phát hiện sớm ung thư vú tại BV Ung Bướu TP.HCM.

Thời gian và địa điểm nghiêncứu: Nghiên cứu được tiến hành từ tháng 04/2019 đến tháng 9/2019 tại Khoa Tầm soát Ung thư, BV Ung bướu, TP.HCM.

Cỡ mẫu và phương pháp chọn mẫu: Phương pháp lấy mẫu thuận tiện trong giai đoạn nghiên cứu, quan sát những phụ nữ đến đăng ký khám ở tại Khoa Tầm soát ung thư', gặp trao đổi, gửi các phiếu khảo sát để thu thập thông tin định lượng (240 phiếu) và tổ chức 02 cuộc thảo luận nhóm.

Phương pháp thu thập số liệu: Phát phiếu khảo sát cho người dân đển khám/có nhu cầu tại Khoa Tầm soát ung thư (TSUT), nghiên cứu viên trình bày lý do, cùng phiếu tự nguyên tham gia nghiên cứu. Sau khi hoàn thành, nghiên cứu viên thu lại, kiểm tra những thông tin ghi trên phiếu có hợp lệ, đầy đủ. Bảng câu hỏi hướng dẫn thảo luận nhóm được thiết kê nhằm thu thập thông tin về các yếu tố ảnh hưởng đến khả năng chi trả của phụ nữ.

Phương pháp phân tích số liệu: Số liệu định lượng sau khi thu thập, được thu thập bằng phần mềm Epidata 3.1 và phân tích bằng excel. Số liệu định tính được ghi âm, gỡ băng và phân tích theo chủ đề.

Đạo đức nghiêncứu: Tuân thủ các nguyên tắc, các bước của Hội đồng đạo đức, nghiên cứu đã được thông qua Hội đồng đạo đức của Trường Đại học Y tế Công cộng số: 174/2019/ YTCC-HD3, ngày 18/04/2019.

\section{KẾT QUẢ NGHIÊN CỨU}

1. Đặc điểm của đối tượng tham gia nghiêncứu. Nghiên cứu được tiến hành thu thập số liệu từ 240 phụ nữ có nhu cầu thực hiện việc khám tư vấn và phát hiện sớm ung thư tuyến vú tại Khoa Tầm soát Ung thư, Bệnh viện Ung bướu TP.HCM.

Bảng 1: Thông tin chung của đôi tượng tham gia khảo sát

\begin{tabular}{|c|c|c|c|c|c|}
\hline Đặc điểm nhân khẩu học & $\begin{array}{c}\text { Tân số } \\
\text { (n) }\end{array}$ & Tỷ lệ (\%) & Đặc điểm nhân khẩu học & $\begin{array}{c}\text { Tân số } \\
\text { (n) }\end{array}$ & $\begin{array}{l}\text { Tỷ lề } \\
(\%)\end{array}$ \\
\hline \multicolumn{3}{|l|}{ Tuổi } & \multicolumn{3}{|c|}{\begin{tabular}{|c|} 
Số lương con \\
\end{tabular}} \\
\hline $18-40$ tuối & 121 & 50,4 & Chưa có & 58 & 24,2 \\
\hline Trên 40 tuối & 119 & 49,6 & 01 nqười con & 49 & 20,4 \\
\hline \multicolumn{3}{|c|}{ Tình trạng hôn nhân } & 02 người con & 86 & 35,8 \\
\hline Đôc thân & 54 & 22,5 & 03 người con & 28 & 11,7 \\
\hline Đã kết hôn & 176 & 73,3 & $>03$ người con & 19 & 7,9 \\
\hline Ly di & 6 & 2,5 & & & \\
\hline Sống chung như vợ chông & 4 & 1,7 & & & \\
\hline \multicolumn{3}{|l|}{ Dân tộc } & \multicolumn{3}{|c|}{ Số người sống cùng nhau trong gia đình } \\
\hline Kinh & 225 & 93,7 & $<=2$ nqười & 22 & 9,1 \\
\hline $\mathrm{Hoa}$ & 10 & 4,2 & Từ 3-5 người & 181 & $\begin{array}{ll}1+1 \\
75,9\end{array}$ \\
\hline Khác & 5 & 2,1 & $>5$ người & 36 & 15,0 \\
\hline \multicolumn{3}{|c|}{ Công việc hiện tại } & \multicolumn{3}{|c|}{ Trình độ học vấncao nhất } \\
\hline Cán bô viên chức & 26 & 10,8 & Tiếu hoc & 31 & 12,9 \\
\hline Nhân viền văn phòng & 48 & 20,0 & Trung học cơ sở & 47 & 19,6 \\
\hline
\end{tabular}




\begin{tabular}{|c|c|c|c|c|c|}
\hline Công nhân & 38 & 15,8 & Trung học phố thông & 52 & 21,7 \\
\hline Nông dân & 23 & 9,6 & Trung cấp & 32 & 13,3 \\
\hline Nghề tự do & 47 & 19,6 & Đai hoc, cao đằng & 77 & 32,1 \\
\hline Khác & 58 & 24,2 & Sau Đại học & 1 & 0,4 \\
\hline \multicolumn{3}{|c|}{ Tống thu nhập hàng tháng của toàn bộ gia đình } & \multicolumn{3}{|c|}{ Thu nhập trung bình môi tháng } \\
\hline Dưới 10 triệu & 75 & 31,3 & Dưới 5 triệu & 103 & 42,9 \\
\hline Từ 10 - dưới 30 triệu & 138 & 57,5 & Từ 5 - dưới 15 triệu & 126 & 52,5 \\
\hline Từ 30 - dưới 60 triệu & 23 & 9,6 & Từ 15 - dưới 30 triệu & 8 & 3,3 \\
\hline$>=60$ triệu & 4 & 1,6 & $>=30$ triệu & 3 & 1,3 \\
\hline
\end{tabular}

Đối tượng tham gia khảo sát có tỷ lệ phụ nữ trong độ tuổi 18 - 40 và trên 40 ngang nhau, trong đó, có đến $73,3 \%$ đã kết hôn, hầu hết là dân tộc kinh với 93,8\%, đa dạng về nghề nghiệp với thu nhập trung bình mỗi tháng rơi vào khoảng 5 triệu đến dưới 15 triệu $(52,5 \%)$. Khi được hỏi về thu nhập trung bình mối tháng của toàn bộ gia đình, thì có 138 gia đình thu nhập từ 10 triệu đến dưới 30 triệu (57,5\%); kế đến có 75 gia đình thu nhập dưới 10 triẹu $(31,3 \%)$; mức thu nhập từ 30 triệu trở lên chiếm $11,2 \%$.

2. Khả năng chi trả để sử dụng gói khám.

Khả năng chi trả khi sử dụng tất cả các dịch vụ gói khám cơ bản. Giá niêm yết của các dịch vụ của gói khám cơ bản được thiết lập theo các quy định của Bộ y tế và tính toán cân đối củabệnh viện (4).Khi được hỏi về khả năng chi trả nếu giá cho các dịch vụ khám cơ bản của gói TSUT vú được niêm yết là: 820.000 đồng thì có 209 người khảo sát trả lời có $(87,1 \%)$. Khi tăng giá $10 \%$ thì tỷ lệ trả lời có giảm đi nhanh chóng, còn $43,3 \%$; nếu tăng giá $20 \%$ thì tỷ lệ này chỉ còn $18,8 \%$; ngược khi nếu giảm giá $10 \%$ thì có 211 người trả lời có $(87,9 \%)$; nếu giảm giá $20 \%$ thì có 221 người trả lời có $(92,1 \%)$.

Khả năng chi trả khi sử dụng từng dịch vu riêng lẻ của gói khám cơ bản. Khi hỏi về khả năng chi trả theo giá niêm yết cho từng dịch vụ riêng lẻ của gói "Khám tầm soát Ung thư vú" thì lần lượt 89,2\%, 85,4\%,85\% người trả lời có khả năng chi trả để khám tầm soát ung thư vú, Siêu âm Doppler màu mạch máu [tuyến vú - nách] và chụp Xquang tuyến vú [1 bên 2 phim].Tỷ lệ người trả lời có khả năng chi trả cho từng dịch vụ riêng lẻ khi thay đổi giá tăng $10 \%$ hay $20 \%$ đều giảm dần, và ngược lại, khi giảm giá dịch vụ $10 \%$ hay $20 \%$ thì tỷ lệ này lại tăng lên.

3. Yếu tố ảnh hưởng đến khả năng chi trả cho dịch vụ tư vấn và phát hiện sớm ung thư vú

\begin{tabular}{|c|c|c|}
\hline Nội dung & Tân số (n) & Tỷ lệ(\%) \\
\hline \multicolumn{3}{|c|}{$\begin{array}{l}\text { Người thân trong gia đình có ai mắc } \\
\text { bệnhung thư }\end{array}$} \\
\hline Có & 77 & 32,1 \\
\hline
\end{tabular}

\begin{tabular}{|c|c|c|}
\hline Không & 163 & 67,9 \\
\hline \multicolumn{3}{|c|}{$\begin{array}{l}\text { Có bị tác động từ gia đình, người thân để ế } \\
\text { sử dung gói khám và tâm soát ung thư vứ }\end{array}$} \\
\hline Có & 117 & 48,8 \\
\hline Không & 123 & 51,2 \\
\hline \multicolumn{3}{|c|}{$\begin{array}{l}\text { Việc khám và tâm soát sớm có thế hân chế } \\
\text { nguycơ bi mắc bệnh ung thư vú }\end{array}$} \\
\hline Đồng ý & 202 & 84,2 \\
\hline Không đồng ý & 5 & 2,1 \\
\hline Không biết & 33 & 13,7 \\
\hline \multicolumn{3}{|c|}{$\begin{array}{l}\text { Thu nhâp của bản thân/gia đình ảnh } \\
\text { hưởngđến khả năng chi trả }\end{array}$} \\
\hline Có & 223 & 92,9 \\
\hline Không & 14 & 5,8 \\
\hline Không rõ & 3 & 1,3 \\
\hline \multicolumn{3}{|c|}{$\begin{array}{l}\text { Giá của gói dịch vụ được niêm yết } \\
\text { ảnhhưởngđến khả năng chi trả }\end{array}$} \\
\hline Có & 186 & 77,5 \\
\hline Không & 41 & 17,1 \\
\hline Không rõ & 13 & 5,4 \\
\hline
\end{tabular}

Uy tín của cớ sở y tế ảnh hưởng đến khả năngchi trả

\begin{tabular}{|c|c|c|}
\hline Có & 214 & 89,2 \\
\hline Không & 14 & 5,8 \\
\hline Không rõ & 12 & 5,0 \\
\hline
\end{tabular}

Tính chất bệnh ảnh hưởng đến khả năng
chi trả

\begin{tabular}{|c|c|c|}
\hline Có & 181 & 75,4 \\
\hline Không & 15 & 6,3 \\
\hline Không rõ & 44 & 18,3 \\
\hline
\end{tabular}

Trong số 240 người được hỏi thì có 77 người $(32,1 \%)$ có người thân trong gia đình mắc bệnh ung thư', 117 người $(48,4 \%)$ bị tác động từ gia đình, ngườithânkhi lựa chọn sử dụng gói khám và tầm soát ung thư vú. Có 202 người $(84,2 \%)$ đồng ý cho rằng việc khám và tầm soát sớm có thể hạn chế nguy cớ bị mắc bệnh ung thư vú. Có 223 người được khảo sát $(92,9 \%)$ đồng ý rằng thu nhập của bản thân/gia đình; 186 người được khảo sát $(77,5 \%)$ đồng ý là giá của gói dịch vụ được niêm yêt; 214 người được khảo sát $(89,2 \%)$ đồng ý rằng uy tín của cở sở y tế; 181 người được khảo sát $(75,4 \%)$ đồng ý rằng tính chất bệnh (loại bệnh đặc thù bắt buộc phải khám tầm soát) sẽ ảnh hưởng khả năng chi trả 
cũng như việc lựa chọn sử dụng gói khám.

Kết quả nghiên cứu định tính làm rõ hơn về khả năng chi trả của người sử dụng dịch vụ. Người dân đã có tham khảo giá, nội dung của gói khám từ các cơ sở y tế khác và lựa chọn dựa vào yếu tố uy tín từ bệnh viện Ung bướu. "Trước khi đến đây khám TSUT tôi cũng có tham khảo nội dung của gói khám và chi phí của các cơ sở y tế khác, tuy nhiên ở Tp. HCM thì chưa có cơ sở khám chữa bệnh nào thực hiện gói khám TSUT giống như Bệnh viện Ưng bướu, giá của gói khám TSUT vú này tôi thấy phù hợp và đây là một Bệnh viện lớn có Uy tín nên tổi quyết định đển đây khám TSUT." (TLN - 01).

Chi phí của gói khám phù hợp với thu nhập và khả năng chi trả hiện nay. "Tôi nghĩ chi phí cho gói khám tư vấn phát hiện sớm ung thư vú hiện đang ápdụng820.000 đồng là hoàn toàn phù hợp." (TLN - 02).

"Chi phí của gói khám hoàn toàn phù hợp với khả năng chi trả của tôi, tôi sẵn sàng chi trả tiền để sử dụng gói khám TSUT này." (TLN - 01).

Ngoài ra, người sử dụng sắn sàng thực hiện thêm các chỉ định khác khi có đề nghị từ Bác sĩ để đảm bảo việc chẩn đoán là chính xác nhất. "Tôi sẵn sàng chi trả để thực hiện các dịch vụ khác ngoài gói khám cơ bản theo chỉ định của bác sĩ, vì bác sĩ nhận thấy có dấu hiệu bất thường nên mới chỉ định thêm các dịch vụ khác, để kiểm tra kỹ hơn về tình trạng bệnh và tư vấn hướng điêu trị tốt nhất cho tôi." (TLN - 01).

Người sử dụng dịch vụ đánh giá cao về tầm quan trọng của gói khám và sẵn sàng chi trả cũng như giới thiệu người thân thực hiện gói khám tại bệnh viện Ung Bướu. "Tôi rất hài lòng về chất lượng và giá của gói khám TSUT vú, bác sĩ khám rất kỹ lưỡng, nhân viên y tế nói chuyện rất nhỏ nhẹ hướng dẫn tận tình." (TLN - 01). "Tôi rất sẵn lòng giới thiệu người khác biết về gói khám TSUT này tai bệnh viê̂n, vì chất lượng gói khám và chi phí phù hợp." (TLN - 02).

Khi được hỏi nếu giá gói dịch vụ và tăng thì có tiếp tục lựa chon sử dung hay không thì người dân cho biết tùy vào mức tăng có phù hợp hay không cũng như so sánh với các cơ sở y tế khác để quyết định. "Chúng tôi nghĩ rằng, nếu giá gói dich vụ tăng thì chắc do những yếu tố nào đó từ $\mathrm{BV}$ cần phải điều chỉnh, tuy nhiên tôi nghĩ mức tăng phải phù hợp so với điều kiện kinh tế của người sử dụng cũng như so với giá của các bênh viện khác, nếu mà quá cao thì chúng tôi sẽ xem xét lại và cân nhắc lựa chọn nơi khác để sử dụng dịch vụ này"(TLN - 02).

\section{Yếu tố cá nhân ảnh hưởng đến khả năng chi trả}

\begin{tabular}{|c|c|c|c|c|}
\hline \multirow{2}{*}{ Đặc điểm nhân khẩu } & \multicolumn{2}{|c|}{ Khả năng chi trả } & \multirow{2}{*}{$\begin{array}{c}\text { OR } \\
\text { KTC }(95 \%)\end{array}$} & \multirow{2}{*}{$p$ value } \\
\hline & Có n (\%) & Không n (\%) & & \\
\hline 18-40 tuối & $110(90,9)$ & $11(9,1)$ & \multirow{2}{*}{$\begin{array}{c}1,092 \\
(0,411 ; 2,905)\end{array}$} & \multirow{2}{*}{0,859} \\
\hline$>40$ tuối & $99(83,2)$ & $20(16,8)$ & & \\
\hline Tình trạng hôn nhân: Đã kết hôn & $152(86,4)$ & $24(13.6)$ & \multirow{2}{*}{$\begin{array}{c}0,581 \\
(0,229 ; 1,473)\end{array}$} & \multirow{2}{*}{0,253} \\
\hline Khác (độc thân, ly di) & $57(89,2)$ & $7(10,8)$ & & \\
\hline Số lượng người con: Chưa có & $54(93,1)$ & $4(6,9)$ & \multirow{3}{*}{$\begin{array}{c}1,570 \\
(0,199 ; 12.418)\end{array}$} & \multirow{2}{*}{0,669} \\
\hline Có từ 1 người con trở lên & $155(85,2)$ & $27(14,8)$ & & \\
\hline \multicolumn{4}{|l|}{ Số người sống cùng trong gia đình } & \\
\hline$<=2$ người & $16(72,7)$ & $6(27,3)$ & \multirow{3}{*}{$\begin{array}{c}1,040 \\
(0,724 ; 1,494)\end{array}$} & \multirow{3}{*}{0,832} \\
\hline Từ 3-5 người & $164(90,1)$ & $18(9,9)$ & & \\
\hline$>5$ người & $29(80,6)$ & $7(19,4)$ & & \\
\hline Công việc hiện tại: Cán bộ viên chức & $25(96,2)$ & $1(3,8)$ & \multirow{6}{*}{$\begin{array}{c}0,742 \\
(0,554 ; 0,994)\end{array}$} & \multirow{6}{*}{0,046} \\
\hline Nhần viền văn ph & $45(93,8)$ & $3(6,3)$ & & \\
\hline Công nhân & $30(78,9)$ & $8(21,1)$ & & \\
\hline Nông dân & $21(91,3)$ & $2(8,7)$ & & \\
\hline Nghề tự do & $44(93,6)$ & $3(6,4)$ & & \\
\hline Khác & $44(75,9)$ & $14(24,1)$ & & \\
\hline \multicolumn{5}{|l|}{ Thu nhập trung bình môi tháng } \\
\hline Dưới 5 triệu & $86(83,5)$ & $17(16,5)$ & \multirow{3}{*}{$\begin{array}{c}0,589 \\
(0,242 ; 1,433)\end{array}$} & \multirow{3}{*}{0,243} \\
\hline Từ 5 - dưới 15 triệu & $114(90,5)$ & $12(9,5)$ & & \\
\hline Từ 15 triêu trở lền & $9(81,8)$ & $2(18,2)$ & & \\
\hline \multicolumn{5}{|l|}{ Tống thu nhập toàn gia đình } \\
\hline Dưới 10 triệu & $57(76,0)$ & $18(24,0)$ & \multirow{3}{*}{$\begin{array}{c}2,599 \\
(1,080 ; 6,252)\end{array}$} & \multirow{3}{*}{0,033} \\
\hline Từ 10 - dưới 30 triệu & $127(92,0)$ & $11(8,0)$ & & \\
\hline Từ 30 triệu trở lên & $25(92,6)$ & $2(7,4)$ & & \\
\hline
\end{tabular}




\begin{tabular}{|c|c|c|c|c|}
\hline \multicolumn{5}{|l|}{ Trình độ học vấn } \\
\hline Cao đẳng, đại học, sau đại học & $73(93,6)$ & $5(6,4)$ & 1,036 & 0857 \\
\hline Khác (Tiếu học, THCS, THPT, trung cấp) & $136(84,0)$ & $26(16,0)$ & $(0,716 ; 1,498)$ & 0.032 \\
\hline Dân tộc: $\quad$ Kinh & $195(86,7)$ & $30(13,3)$ & 2,263 & 0.370 \\
\hline Khác & $14(93,3)$ & $1(6,7)$ & $(0,380 ; 13,491)$ & \\
\hline
\end{tabular}

Có sự khác biệt có ý nghĩa thống kê giữa khả năng chi trả của phụ nữ với các nhóm nghề nghiệp (với $p=0,046<0,05$ ), thu nhập trung bình của toàn bộ gia đình $(p=0,033<0,05)$. Tuy nhiên, không tìm thây sự khác biệt có ý nghĩa thống kê giữa khả năng chi trả của phụ nữ với độ tuổi, tình trạng hôn nhân, số người sống cùng nhau, số lượng người con, trình độ học vấn, thu nhập trung bình mỗi tháng của cá nhân, dân tộc.

\section{BÀN LUÂN}

Kết quả nghiên cứu từ 240 phụ nữ có dự định thực hiện việc khám tư vấn và phát hiện sớm ung thư tuyến vú tại Khoa Tầm soát Ung thư, Bệnh viện Ung bướu TP.HCM cho thấy: độ tuối của người tham gia nghiên cứu là đa dạng và cân bằng ở 2 nhóm tuổi từ 18-40 tuổi và trên 40 tuổi. Số lượng phụ nữ đã kết hôn chiếm đa số với $73,3 \%$; phần lớn đều có con chiếm hơn $75 \%$, trong số đó có 2 con chiếm hơn 35\%. Có $75,9 \%$ phụ nữ tham gia khảo sát cho biết có từ 3-5 người sống cùng nhau trong gia đình và đa dạng loại hình công việc hiện tại. Phần lớn thu nhập trung bình hàng tháng rơi vào 2 mức: dưới 5 triệu $(42,9 \%)$ và từ 5 đến dưới 15 triệu (52,5\%). Hơn $57 \%$ người tham gia khảo sát cho biết tổng thu nhập hàng tháng của toàn bộ gia đình rơi vào khoảng từ 10 đến dưới 30 triệu. Phần lớn người tham gia khảo sát là dân tộc kinh chiếm $93,8 \%$ và trình độ học vấn trải dài từ tiểu học đến sau đạihọc.

Bên cạnh đó, 100\% đối tượng tham gia nghiên cứu đều sẵn sàng chi trả tiền túi để thực hiện gói khám nếu dịch vụ chưa được chi trả bởi BHYT, trong đó $90,4 \%$ có thẻ BHYT. Gần $50 \%$ phụ nữ có tham khảo/ so sánh gói khám tư vấn và phát hiện sớm ung thư tuyến vú ở các cơ sở y tế khác, phần lớn trong số đó là tham khảo về giá cả $(71,4 \%)$ và uy tín của cơ sở y tế $(22,3 \%)$.

Ngoài ra, khi xem xét mối liên hệ giữa đặc điểm cá nhấn của đối tượng nghiên cứu và khả năng chi trả thì có 2 nhóm đặc điểm cá nhân có ảnh hưởng gồm: nhóm nghề nghiệp và thu nhập trung bình hàng tháng của toàn bộ gia đình. Cụ thể, có sự khác biệt giữa khả năng chi trả của phụ nữ với các nhóm nghề nghiệp, trong đó nhóm nhân viên văn phòng có khả năng chi trả cao hơn các nhóm nghề nghiệp còn lại là 0,74 lần; có sự khác biệt giữa khả năng chi trả của phụ nữ với thu nhập trung bình của toàn bộ gia đình, trong đó thu nhập trung bình từ 30 triệu trở lên có khả năng chi trả cao hơn các mức thu nhập còn lại là 2,6 lần.

Điều này được giải thích thông qua kết quả thảo luận nhóm với những phụ nữ đã sử dụng gói khám tầm soát ung thư tại Bệnh viện khi họ cho rằng thu nhập của gia đình có tác động không nhỏ đến quyết định khám tầm soát ngay hoặc là lưỡng lự chờ thêm 1 khoảng thời gian nữa.

\section{KẾT LUÂ̂N}

Một số yễu tố ảnh hưởng đến việc lựa chọn cũng như sẵn sàng chi trả để sử dụng gói khám TSUT thì có: $48,4 \%$ bị tác động từ gia đình, người thân khi lựa chọn sử dụng gói khám và tầm soát ung thư vú; $92,9 \%$ đồng ý rằng thu nhập của bản thân/gia đình; $77,5 \%$ đồng ý là giá của gói dịch vụ được niêm yết; $89,2 \%$ đồng ý rằng uy tín của cơ sở y tế và $75,4 \%$ đồng ý rằng tính chất bệnh ảnh hưởng việc lựa chọn sử dụng gói khám tầm soát và phát hiện ung thư tuyến vú.

Kết quả nghiên cứu còn cho thấy, có sự khác biệt giữa khả năng chi trả của phụ nữ với các nhóm nghề nghiệp, trong đó nhóm nhân viên văn phòng có khả năng chi trả cao hơn các nhóm nghề nghiệp còn lại là 0,74 lần; có sự khác biệt giữa khả năng chi trả của phụ nữ với thu nhập trung bình của toàn bộ gia đình, trong đó thu nhập trung bình từ 30 triệu trở lên có khả năng chi trả cao hơn các mức thu nhập còn lại là 2,6 lần.

\section{TÀI LIỆ THAM KHẢO}

1. Bray F., Ferlay J., Soerjomataram I. và cộng sứ. (2018). Global Cancer Statistics 2018: GLOBOCAN Estimates of Incidence and Mortality Worldwide for 36 Cancers in 185 Countries. CA Cancer JClin.

2. Bùi Diệu, Nguyễn Bá Đức, Trân Văn Thuấn và cộng sự (2012). Gánh nặng bệnh ung thư và chiến lược phòng chống ung thư quốc gia đến năm 2020. Tạp Chí Ung Thư Hoc, 1,13-19;

3. Bộ y tế (2016), Báo cáo chung tổng quan ngành y tểJAHR;

4. Bv Ung Bướu, Quyết định số $1232 / Q Đ-B V U B$ ngày 29/05/2018 vế giá gói khám tư vấn và phát hiện sớm ung thư vú tại Khoa Tâm soát Ung thư, B̉v Ung bướuTP.HCM; 